\title{
Characteristics of Parameters in Power Equation Representing Sunny Crown Profile of Hinoki Cypress Tree
}

\author{
Yoshiaki Waguchi*1
}

\begin{abstract}
Characteristics of parameters in power equation $\left(r=a z^{b}\right.$ where $r$ is the crown radius (m) at a given distance $z$ (m) from the tree apex, and $a$ and $b$ are parameters) for representing the sunny crown profile were examined for Hinoki cypress (Chamaecyparis obtusa ENDL.). Three hypothetical models were constructed; Model 1: the values of $a$ and $b$ are unique for each tree, Model 2: the value of $b$ is common to all trees, Model 3: the values of $a$ and $b$ are common to all trees. The three models were compared using AKAIKE's information criterion (AIC) and root mean squared error (RMSE). Data were obtained from 112 sample trees selected in six pure stands of even-aged Hinoki cypress. Model 3 was inferior to the other two models in terms of AIC and RMSE. Model 2 was superior to Model 1 in terms of AIC. Although Model 2 gave a larger value of RMSE than that of Model 1 , the difference was only $0.006 \mathrm{~m}$. When the profile of the sunny crown of a Hinoki cypress tree is represented by the power equation, we can assume that parameter $b$ is invariant between trees and that parameter $a$ varies from tree-to-tree.

Keywords: sunny crown profile, power equation, Hinoki cypress
\end{abstract}

\section{INTRODUCTION}

The organic matter produced by a tree is based on the photosynthetic activity of the foliage. One of the main functions of the tree crown is to position the current foliage and provide for its renewal; the quantity of foliage is closely related to the crown dimensions. Consequently, crown dimensions are strongly correlated with tree volume, height, and diameter growth (MAGUIRE and HANN, 1989). In particular, the sunny crown volume or surface area (volume or surface area of crown exposed to sunlight) is an effective predictor of individual tree volume growth. For example, INOSE (1982) found that the increment in stem volume of Todo-fir (Abies sachalinensis MAST.) could be predicted by the increment of sunny crown volume. KAJIHARA (1985) used sunny crown surface area to predict the increment in stem volume of Japanese cedar (Cryptomeria japonica D. DoN).

Sunny crown volume and surface area can be estimated by rotating the sunny crown profile on the trunk axis. However, obtaining an accurate profile is difficult because of irregularities. To estimate sunny crown volume and surface area, it would be convenient to represent the sunny crown

\footnotetext{
${ }^{* 1}$ Nara Forest Research Institute, Takatori, Nara 635-0133, Japan
}

profile as a mathematical equation. The general structure of a sunny crown profile is based on an assumed allometric relationship between the horizontal length of a branch and the distance from its insertion on the bole to the tree apex (MrTchell, 1969; INOSE, 1982). The following power equation is often used for conifers:

$$
r=a z^{b}
$$

where $r$ is the crown radius $(\mathrm{m})$ at a given distance $z(\mathrm{~m})$ from the tree apex, and $a$ and $b$ are parameters. RAULIER $e t$ al. (1996) fitted the eq. (1) to sunny crown profiles of black spruce (Picea mariana BSP). INOSE (1982) fitted the following equation to sunny crown profiles of Todo-fir:

$$
z=a^{\prime} r^{b^{\prime}}
$$

where $a^{\prime}$ and $b^{\prime}$ are parameters. MizunAGA $(1992,1998)$ also fitted the eq. (2) to sunny crown profiles of Japanese cedar and Hinoki cypress (Chamaecyparis obtusa ENDL.). Their studies showed the fit of crown profiles with eq. (1) or eq. (2) for these species was good.

Another merit of representing sunny crown profile using an equation is that the profile can be predicted from estimates equation parameters. Consequently, based on the principle of parsimony, we should choose an equation with the smallest number of parameters. The value of parameter $b$ ' in eq. (2) for Japanese cedar and Hinoki cypress is a constant within the species irrespective of size and age crass (MIzunAGA, 1992; 
1998). No significant differences were detected in the means for both parameters $a^{\prime}$ and $b$ ' in eq. (2) between Todo-fir stands (INOSE, 1982). These studies suggest that it is may be fair to assume that the common parameter values in eq. (1) or eq. (2) can be adopted to all trees within a species regardless of stand and individual attributes. Although the adequacy of this assumption has not been tested, if it is true, fewer parameters would be needed to be estimated for each tree.

The purpose of this study is to characterize the parameters in the eq. (1) for representing the sunny crown profile of Hinoki cypress, a widely distributed plantation tree in Japan. To achieve this objective, I constructed and compared three hypothetical models.

\section{MATERIALS AND METHODS}

\section{Data Collection}

Sunny crown profile data were obtained from six pure stands of even-aged Hinoki cypress in Nara Prefecture, Japan. The stand age ranged from 10 to 72 years with a density from 5,250 to 1,000 trees/ha, mean diameter at breast height from 6.8 to $29.1 \mathrm{~cm}$, and mean height from 5.5 to $16.8 \mathrm{~m}$ (Table 1 ). Sample trees (15 to 22 ) were selected at random in each stand; trees ranged from 3.6 to $32.5 \mathrm{~cm}$ in diameter at breast height and from 4.1 to $18.7 \mathrm{~m}$ in total height. Each tree was felled and the crown was divided from the crown base to the tree apex into 1- or 0.5-m deep vertical layers. Each layer was set vertically on the ground and crown radius at the middle of the layer was measured in four directions at right angles using a surveyor's tape.

The crown of a tree can be divided into the upper crown exposed to direct sunlight (sunny crown) and the lower crown in contact with neighboring crowns (shade crown). The separation between sunny and shade crowns has been equated with the top point of crown contact for white spruce (Picea glauca Voss) (MrTchelL, 1969), for Douglas-fir (Pseudotsuga menziesii Franco) (Mitchell, 1975), for Hinoki cypress (KajIHARA, 1981), and for Todo-fir (INOSE, 1982). Therefore, observations below the top point of crown contact were eliminated from the data set. The separation between sunny and shade crowns for each tree was averaged by eye to find the point representing the average height to the top point of crown contact in the contour direction. The separation height was measured with a wide-scale Spiegel relascope before felling. A 5-meter pole was placed upright against the tree trunk for the measurements. Sunny crown length ranged from 1.5 to $7.4 \mathrm{~m}$.

Models

Equation (2) can be rewritten as:

$$
r=a^{-\frac{1}{b^{\prime}}} z^{\frac{1}{b^{\prime}}}
$$

From eqs. (1) and (3), parameters $a$ and $b$ are given by

$$
a=a^{, \frac{1}{b^{\prime}}}, b=\frac{1}{b^{\prime}} .
$$

Consequently, if the parameter $b^{\prime}$ in eq. (2) is common to all trees, parameter $b$ in eq. (1) is common to all trees. Likewise, if the parameters $a^{\prime}$ and $b^{\prime}$ in eq. (2) are common to all trees, parameters $a$ and $b$ in eq. (1) are common to all trees. Therefore, I constructed three hypothetical models to characterize the parameters in eq. (1) for representing the sunny crown profile of Hinoki cypress.

Model 1: The values of $a$ and $b$ are unique for each tree.

Model 2: The value of $b$ is common to all trees.

Model 3: The values of $a$ and $b$ are common to all trees.

\section{Fitting of Models}

The models were fitted using the maximum likelihood method. The sunny crown profile equation for $i$-th sample tree $(i=1,2, \cdots, 112)$ is:

$$
r_{i j k}=a_{i} z_{i j}^{b_{i}}+\varepsilon_{i j k}
$$

where $r_{i j k}$ is the $k$-th crown radius (m) $(k=1,2,3,4)$ on the $j$-th distance $z_{i j}(\mathrm{~m})$ from the apex $\left(j=1,2, \ldots, n_{i}\right), \varepsilon_{i j k}$ is the normal random variable with mean zero and variance $\sigma_{i}{ }^{2}$, and $a_{i}$ and $b_{i}$ are parameters. The log likelihood is given by:

Table 1 Stand descriptions

\begin{tabular}{cccccc}
\hline Stand & $\begin{array}{c}\text { Age } \\
\text { (year) }\end{array}$ & $\begin{array}{c}\text { Density } \\
\text { (trees/ha) }\end{array}$ & $\begin{array}{c}\text { Mean diameter } \\
\text { at breast height } \\
(\mathrm{cm})\end{array}$ & $\begin{array}{c}\text { Mean total } \\
\text { height } \\
(\mathrm{m})\end{array}$ & $\begin{array}{c}\text { Number of } \\
\text { sample trees }\end{array}$ \\
\hline A & 10 & 5,250 & 6.8 & 5.5 & 20 \\
B & 16 & 3,006 & 11.8 & 10.1 & 15 \\
C & 19 & 3,828 & 11.9 & 9.4 & 20 \\
D & 29 & 2,602 & 12.6 & 12.7 & 22 \\
E & 41 & 1,820 & 18.6 & 16.4 & 15 \\
F & 72 & 1,000 & 29.1 & 16.8 & 20 \\
\hline
\end{tabular}




$$
\begin{aligned}
l\left(a_{1}, a_{2}, \ldots, a_{112}, b_{1}, b_{2}, \ldots, b_{112}, \sigma_{1}^{2}, \sigma_{2}^{2}, \ldots, \sigma_{112}^{2}\right) \\
=-\frac{1}{2} \sum_{i=1}^{112} 4 n_{i} \log 2 \pi-\frac{1}{2} \sum_{i=1}^{112} 4 n_{i} \log \sigma_{i}^{2} \\
-\frac{1}{2} \sum_{i=1}^{112}\left\{\frac{1}{\sigma_{i}^{2}} \sum_{j=1}^{n_{i}} \sum_{k=1}^{4}\left(r_{i j k}-a_{i} z_{i j}^{b_{i}}\right)^{2}\right\} .
\end{aligned}
$$

To obtain the maximum likelihood estimates, we must find the values of parameters that maximize the $\log$ likelihood. If the value of $\sigma_{i}{ }^{2}$ is common to all sample trees (i.e., $\sigma_{1}{ }^{2}=\sigma_{2}{ }^{2}=\ldots=\sigma^{2}$ ${ }_{112}=\sigma^{2}$ ), the $\log$ likelihood is maximized with respect $a_{i}$ and $b_{i}$ when

$$
S=\sum_{i=1}^{112} \sum_{j=1}^{n_{i}} \sum_{k=1}^{4}\left(r_{i j k}-a_{i} z_{i j}^{b_{i}}\right)^{2}
$$

is minimized. In this case, the maximum likelihood method is equivalent to the ordinary least squares method and the maximum likelihood estimates $\hat{a}_{i}$ and $\hat{b}_{i}$ are obtained by solving

$$
\frac{\partial S}{\partial \hat{a}_{i}}=0, \frac{\partial S}{\partial \hat{b}_{i}}=0
$$

Since eq. (1) is non-liner with respect to its parameters $a$ and $b$, an iterative procedure is necessary for solving eq. (8). As the procedure, GAUSS-NEwTON method was used.

The value of $\sigma^{2}$ maximizes the $\log$ likelihood in eq. (6) when

$$
\frac{\partial l}{\partial \sigma^{2}}=-\frac{1}{2 \sigma^{2}} \sum_{i=1}^{112} 4 n_{i}+\frac{1}{2\left(\sigma^{2}\right)^{2}} \sum_{i=1}^{112} \sum_{j=1}^{n_{i}} \sum_{k=1}^{4}\left(r_{i j k}-\hat{a}_{i} z_{i j}^{b_{i}}\right)^{2}=0
$$

Therefore, the maximum likelihood estimate $\hat{\sigma}^{2}$ is

$$
\hat{\sigma}^{2}=\frac{1}{\sum_{i=1}^{112} 4 n_{i}} \sum_{i=1}^{112} \sum_{j=1}^{n_{i}} \sum_{k=1}^{4}\left(r_{i j k}-\hat{a}_{i} z_{i j}^{\hat{b}_{j}}\right)^{2} .
$$

Model 2 and 3 are special cases in which $b_{1}=b_{2}=\ldots=b_{112}=b$ for Model 2, $a_{1}=a_{2}=\ldots=a_{112}=a$ and $b_{1}=b_{2}=\ldots=b_{112}=b$ for Model 3 .

\section{Model Evaluation}

The three models were compared using AKAIKE's information criterion (AIC, SAKAMOTO et al., 1986), defined as

$$
\mathrm{AIC}=-2(\text { maximum } \log \text { likelihood })+2 m
$$

where $m$ is the number of parameters in the models. From eqs. (6) and (10), the maximum $\log$ likelihood is given by:

$$
\begin{aligned}
& l\left(\hat{a}_{1}, \hat{a}_{2}, \ldots, \hat{a}_{112}, \hat{b}_{1}, \hat{b}_{2}, \ldots, \hat{b}_{112}, \hat{\sigma}^{2}\right) \\
& \quad=-\frac{1}{2} \sum_{i=1}^{112} 4 n_{i} \log 2 \pi-\frac{1}{2} \sum_{i=1}^{112} 4 n_{i} \log \hat{\sigma}^{2}-\frac{1}{2} \sum_{i=1}^{112} 4 n_{i} .
\end{aligned}
$$

From eqs. (11) and (12), the AIC of the models is given by

$$
\mathrm{AIC}=\sum_{i=1}^{112} 4 n_{i} \log 2 \pi+\sum_{i=1}^{112} 4 n_{i} \log \hat{\sigma}^{2}+\sum_{i=1}^{112} 4 n_{i}+2 m .
$$

Generally, goodness of fit increases as the number of parameters in a model increases. Consequently, the fourth term on the right side of eq. (13) incurs a penalty against increasing the number of parameters. Model 1 has $225\left(\hat{a}_{1}, \hat{a}_{2}\right.$, $\ldots, \hat{a}_{112}, \hat{b}_{1}, \hat{b}_{2}, \ldots, \hat{b}_{112}$, and $\left.\hat{\sigma}^{2}\right)$; Model 2 has $114\left(\hat{a}_{1}, \hat{a}_{2}, \ldots, \hat{a}_{112}, \hat{b}\right.$, and $\left.\hat{\sigma}^{2}\right)$, Model 3 has three $\left(\hat{a}, \hat{b}\right.$, and $\left.\hat{\sigma}^{2}\right)$. When using this criterion, the model with the smallest AIC is presumed to be the best.

The root mean squared error (RMSE) was also used to find the best model. RMSE was calculated as:

$$
\operatorname{RMSE}=\sqrt{\frac{S}{\sum_{i=1}^{112} 4 n_{i}}} .
$$

\section{RESULTS AND DISCUSSION}

Model 2 has the minimum AIC while Model 1 has the minimum RMSE (Table 2). Model 3 was inferior to the other two models in terms of AIC and RMSE and is inappropriate for representing the sunny crown profile of Hinoki cypress tree.

The particular shape taken by eq. (1) depends on the value of parameter $b$; a value of 1.0 forms a crown with a conic shape, and a value of 0.5 forms a parabolic shape. MizunAGA (1998) reported that the shape of the sunny crown of Hinoki cypress tree is somewhere between a cone and quadratic paraboloid. The value of parameter $\hat{b}$ estimated by Model 2 is 0.686 , which is in good agreement with the result found by MizUNAGA (1998).

Table 2 Parameter estimates, AKAIKE's information criterions (AIC), and root mean squared errors (RMSE) for models

\begin{tabular}{ccccc}
\hline \multirow{2}{*}{ Model } & \multicolumn{2}{c}{ Parameter } & \multirow{2}{*}{ AIC } & \multirow{2}{*}{ RMSE } \\
\cline { 2 - 3 } & $a$ & $b$ & & \\
\hline 1 & $0.575 \pm 0.151^{*}$ & $0.701 \pm 0.136^{*}$ & $-2,087$ & 0.141 \\
2 & $0.581 \pm 0.134^{*}$ & 0.686 & $-2,141$ & 0.147 \\
3 & 0.573 & 0.667 & -63 & 0.239 \\
\hline
\end{tabular}

Note: ${ }^{*}$ Mean \pm SD 
The parameter $a$ in eq. (1) along with the power $b$ governs the rate of change of crown radius with distance from the apex. The larger the value of parameter $a$, the greater the rate of change in crown radius. In other words, when the value of parameter $b$ is common to all trees, the larger values of parameter $a$ indicate a more obtuse or wide "umbrella-like" crown profile. There was a significant difference in the parameter $a$ estimated by Model 2 among the stands (Table 3, one-way ANOVA, $F=26.7, P<0.01$ ). Trees in older stands had larger values of parameter $a$ than trees in younger stands, indicating that older Hinoki cypress trees generally had a more obtuse sunny crown than younger trees. Apical obtuseness with increasing age has also been reported for Hinoki cypress tree by Kryono (1990) and Mizunaga (1998), suggesting that Model 2 can be used to represent the sunny crown profile of Hinoki cypress trees.

Although Model 2 gave a larger value of RMSE than that of Model 1, the difference was only $0.006 \mathrm{~m}$ (Table 2). If a common value of parameter $b$ is assumed for all trees, parameter $a$ would completely determine the profile of the sunny crown Hinoki cypress trees. In other words, if a value of parameter $b$ was available for Hinoki cypress tree, a sunny crown profile could be constructed simply by varying parameter $a$, each profile being identified by a different value of parameter $a$. Considering this advantage, we might be able to ignore the very small difference in RMSE between Model 1 and Model 2 and conclude that Model 2 is the best of the three constructed models. When the profile of the sunny crown of a Hinoki cypress tree is represented by eq. (1), we can assume that parameter $b$ is invariant between trees and that parameter $a$ varies from tree-to-tree.

Table 3 Means of parameter estimates for Model 2

\begin{tabular}{ccc}
\hline \multirow{2}{*}{ Stand } & \multicolumn{2}{c}{ Parameter } \\
\cline { 2 - 3 } & $a^{*}$ & $b$ \\
\hline A & $0.476 \pm 0.067$ & 0.686 \\
B & $0.490 \pm 0.061$ & 0.686 \\
C & $0.496 \pm 0.079$ & 0.686 \\
D & $0.608 \pm 0.074$ & 0.686 \\
E & $0.706 \pm 0.116$ & 0.686 \\
F & $0.717 \pm 0.129$ & 0.686 \\
\hline
\end{tabular}

Note: ${ }^{*}$ Mean $\pm \mathrm{SD}$

\section{ACKNOWLEDGEMENTS}

I thank Dr. M. UEDA of Nara Forest Research Institute for his help with the field study.

\section{LITERATURE CITED}

INoSE, M., (1982): A tree growth model based on crown competition in Todomatsu (Abies sachalinensis). I. The relationship between crown development and volume increment. Bull. For. For. Prod. Res. Inst. 318: 103-127

KaJiHARA, M., (1981): Crown form, crown structure and the relationship between crown dimensions and leaf fresh weight of hinoki (Chamaecyparis obtusa). Bull. Kyoto Pref. Univ. For. 25: 1128

KAIIHARA, M., (1985): Estimation of stem-volume increment by using sunny crown-surface area and stem-surface area. J. Jpn. For. Soc. 67: $501-505$

Kryono, Y., (1990): Dynamics and control of understories in Chamaecyparis obtusa plantations. Bull. For. For. Prod. Res. Inst. 359: 1-122

Maguire, D.A. and Hann, D.W., (1989): The relationship between gross crown dimensions and sapwood area at crown base in Douglas-fir. Can. J. For. Res. 19: 557-565

Mitchell, K.J., (1969): Simulation of the growth of even-aged stands of white spruce. Bull. Yale Univ. Sch. For. 75: 1-48

MrTchell, K.J., (1975): Dynamics and simulated yield of Douglas-fir. For. Sci. Monogr. 17: 1-39

Mizunaga, H., (1992): Prediction of thinning effect by canopy model. I. Canopy surface structure dynamics after thinning. J. Jpn. For. Soc. 74: 314-324

Mizunaga, H., (1998): Evaluation of thinning system by canopy dynamic model. Bull. Okayama Pref. For. Exp. Sta. 14: 1-49

Raulier, F., UnG, C.H. and Ouellet, D., (1996): Influence of social status on crown geometry and volume increment in regular and irregular black spruce stands. Can. J. For. Res. 26: 1,742-1,753

(Received 28 January 2004)

(Accepted 19 May 2004) 